\title{
Making Science Education Accessible to All
}

\author{
Zafra Margolin Lerman, PhD, FRSC \\ Malta Conferences Foundation
}

\section{ABSTRACT}

Many students shy away from science. In order to attract students into studying science, creative methods for teaching and learning were developed for all levels of education, from primary school to university, and from formal to informal settings. These methods utilize the students' talents, hobbies, interests and cultural backgrounds. Equal access to science education is a human right that belongs to all $[1,2]$. If we do not guarantee science education to all, we will form a two-class society divided not by royalty and status, but by knowledge of science. The centerpiece for this method is the development of student projects, which help them to remember and understand abstract scientific concepts. An old Chinese proverb says: "I hear and I forget; I see and I remember; I do and I understand." These students' projects take advantage of seeing and remembering, doing and understanding.

Through this process, students are active learners, instead of being passive observers. To demonstrate their understanding of scientific concepts through their projects, the students use a media of their choice, from drawing, dance and drama (no tech) to computer animation (high tech). Projects can also take the form of paintings, sculptures, songs, films, and scripts for theater. These projects are used as alternative assessment methods where the whole class is involved in the assessment process. In order for this method to be successful, workshops for teachers as well as parents must be conducted. This way, the students will be taught in a creative way in school and through the joint involvement of teachers and parents, students will be encouraged to pursue chemistry. After all, "it takes a village to raise a child," as the African proverb states.

\section{Narrative}

The world population is growing in an exponential rate (Figure 1). There are many problems facing the growing world population. We as science educators have the obligation to help solve these problems.

- We must guarantee science education for all.

- We must avoid creating two separate social classes: one that is science literate, and another that is not.

- No single teaching method fits all.

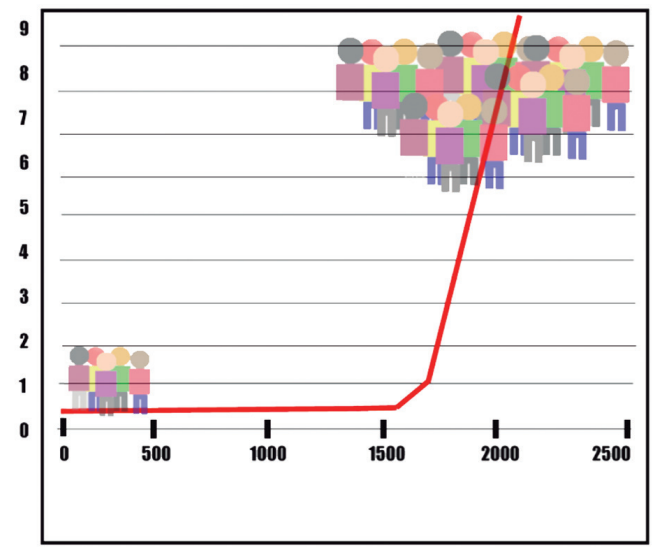

Figure 1 World Population 1AD-2050AD (Billions)
Equal access to science education is a basic human right that belongs to all. Therefore, we must develop methods for teaching, learning, and assessing science, which will take into account the students' talents, interests, and cultural backgrounds [3]. If we will not develop this kind of curricula, we will form two class societies, divided not by royalty and wealth. These two societies would include one with people who have knowledge in science and technology, and can function in the new world, and another would be made up of people who do not have knowledge in science and technology. We must prevent this from happening by working hard on developing the right methods for teaching science.

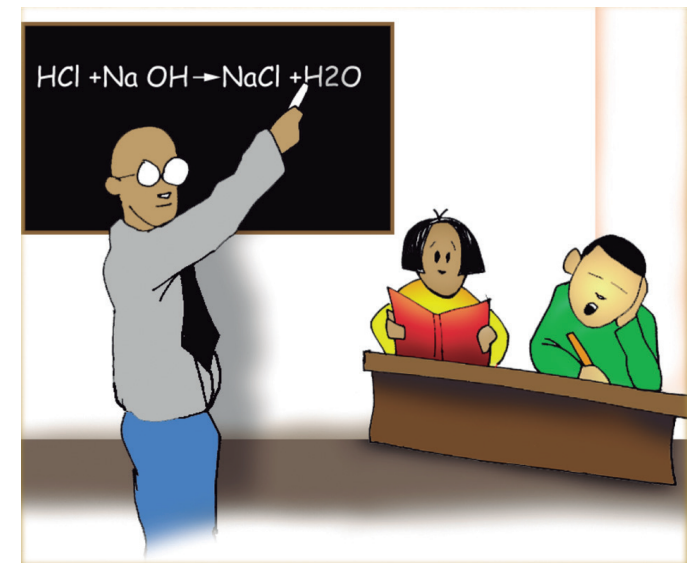

Figure 2 Passive Learning 
With these new methods, students move from a passive mode of learning, which is teacher centered (Figure 2), to an active mode of learning, which is student centered (Figure 3).

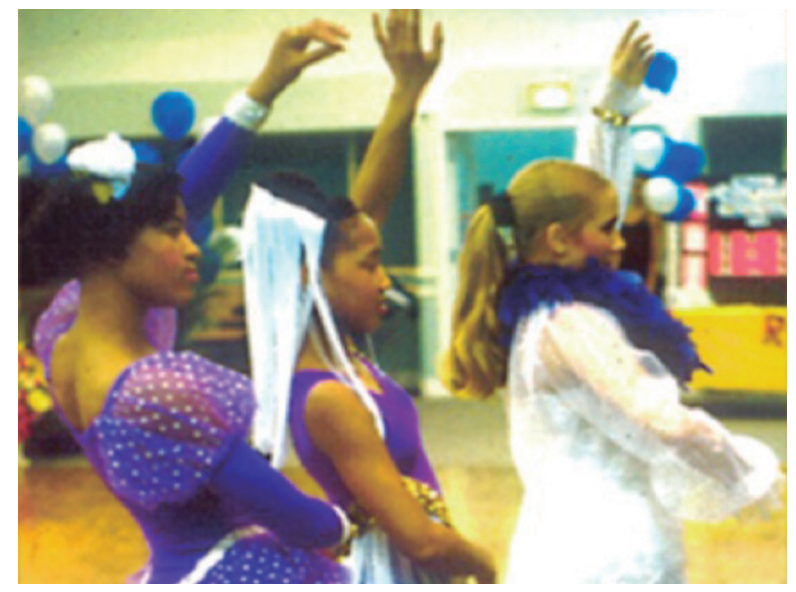

Figure 3 Active Learning

In order to make the science class relevant to the students' lives and environment, every class from grade five to university starts with a report on a scientific issue that they find in the daily newspaper, magazine, or online. Students are asked to summarize the article and present it to the class in a one-minute presentation. In each class the teachers select a group of students to report to the class. This guarantees that the whole class is coming prepared.

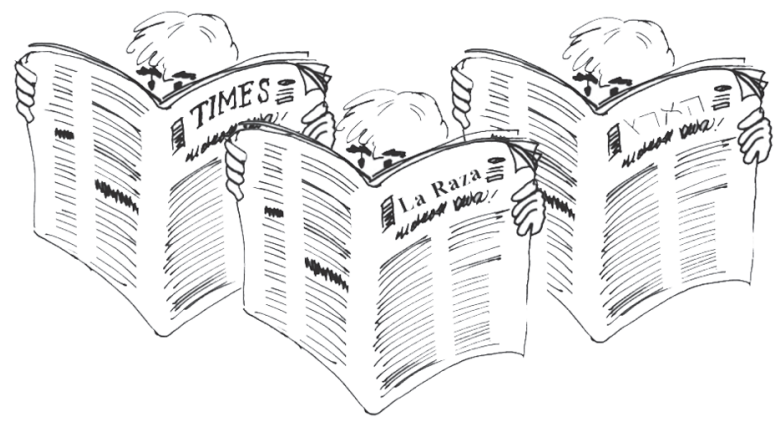

Figure 4 Each class begins with a scientific article from the newspaper

We must emphasize to the students:

- That a basic science background is needed to understand the article.

- That science is part of everyday life.

- That it is important to communicate science accurately.

This exercise helps the students to get into the habit of reading articles about science in newspapers, magazines, and online. This also encourages them to listen to science programs on radio and television. Many times students who graduated come back to say that they are still reading scientific articles, but are lacking a platform to report and discuss these articles. Usually the discussion in class is very lively. It is easy to relate the subject of the day to one of the articles represented. For example, an article on nuclear technology can be a start point for discussing nuclear power plants, nuclear weapons, fission reaction, the nucleus of the atom, and the structure of the atom as a whole. This way students realize that their science class has relevance to their life and is not just a hard class that they have to take.

\section{Student Projects}

A requirement in the science class is that students show their knowledge and understanding of the concept discussed through any mediums of their choice [4]. For example [7], the concept of the chemical bond is presented through a drama parodying the popular movie, "The Godfather," but called " The Bondfather" and featuring a mother begging the Bondfather, Don Mendeleev, to break up the bond between her daughter, Chlorine, and her boyfriend, Sodium. The mother says she is afraid that their relationship will be broken in water and she would like her daughter to be in a covalent bond, where she can share electrons with her partner and have a strong bond with them. The same concept is presented by another drama called "Love Story Between Sodium and Chlorine," following Shakespeare's "Romeo and Juliet." Dance students choreographed a dance on the bond between Sodium and Chlorine. They performed this dance in many venues as shown in Figure 5.

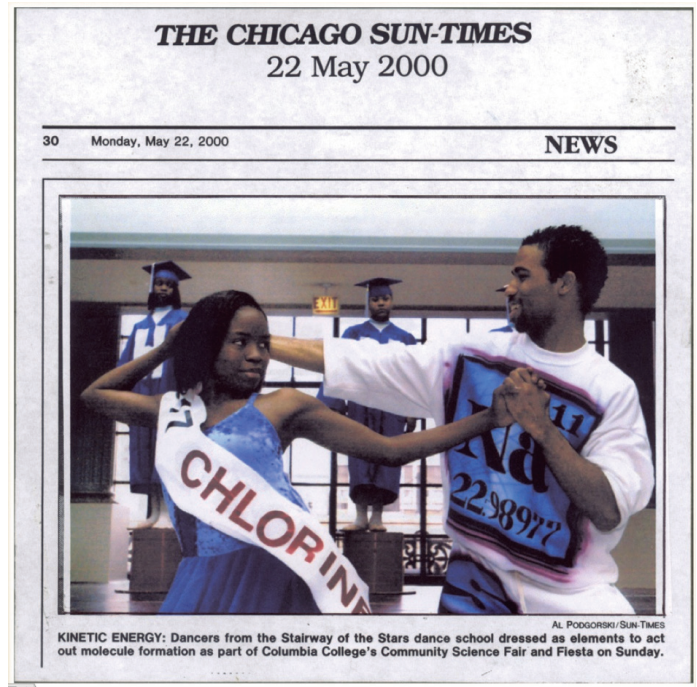

Figure 5 A dance between Sodium and Chlorine

Students produce all their scientific visualizations as seen in Figure 6. Nothing is commercially produced. Students use their talents, interests, and cultural backgrounds as tools to help visualize scientific concepts $[5,6]$.

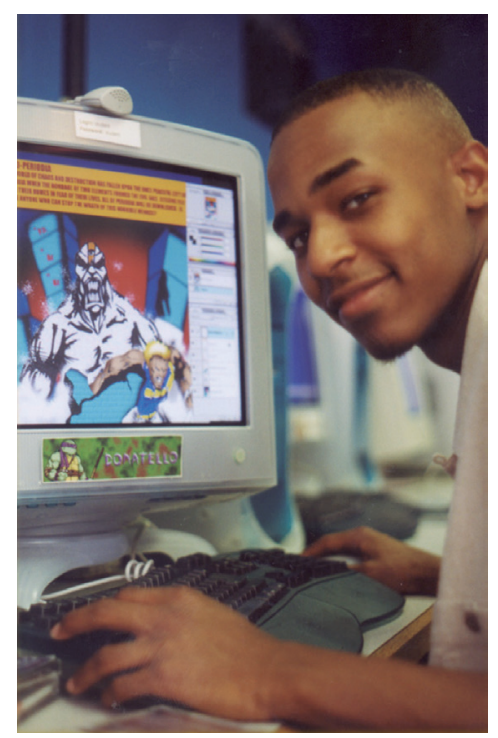

Figure 6 A student producing computer visualizations 
Many times the projects are the result of teamwork to resemble the reality of the workplace. It is extremely important that students learn to work in teams and not just as individuals. Once they are in the workplace, they will have to be part of a team. Figure 7 shows a student's description on teamwork.

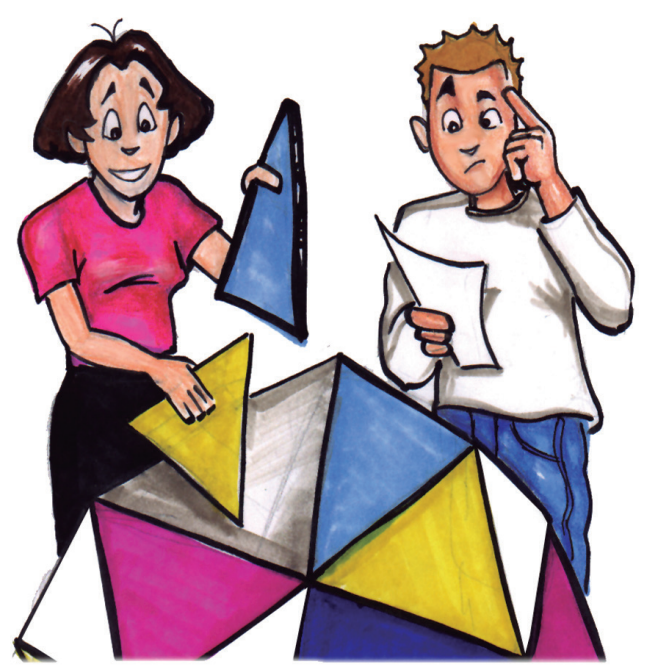

Figure 7 A student produced a cartoon demonstrating teamwork

Many television studios reported on a project produced by seventh grade students who represented the depletion of the ozone layer through dance. The reporters interviewed the students and were amazed on how well they understood the concept after performing their dance (Figure 8). This was shown on television in South Africa, China, WGN, ABC, NBC, and CNN television broadcasts.

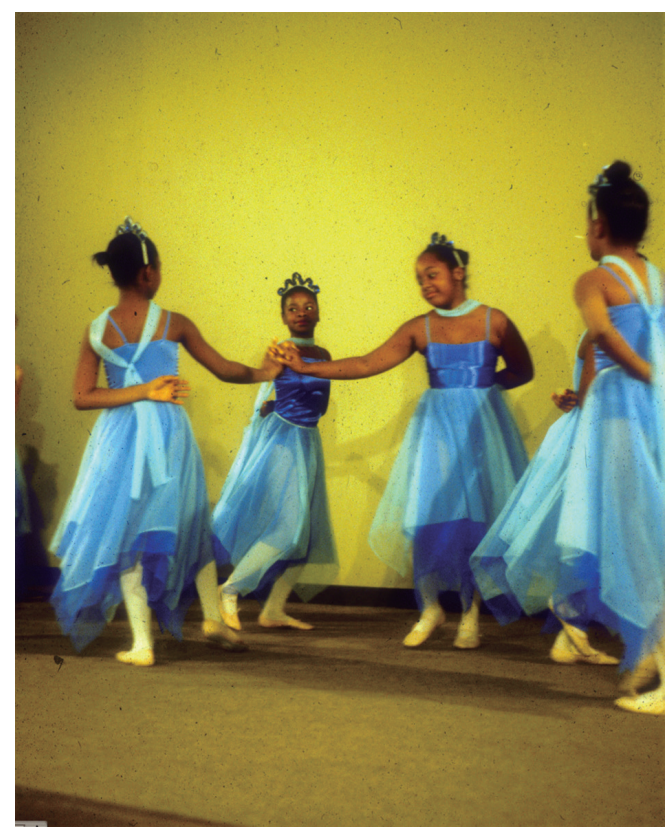

Figure 8 Depletion of the Ozone Layer
One of the student dancers, when interviewed by CNN, said the following statement (Figure 9): "After I was on stage... My cousin played one of the atoms. And she was splitting them and everything and I was like 'oh, that's how that works.' I never knew nothing about it until I did the dance."

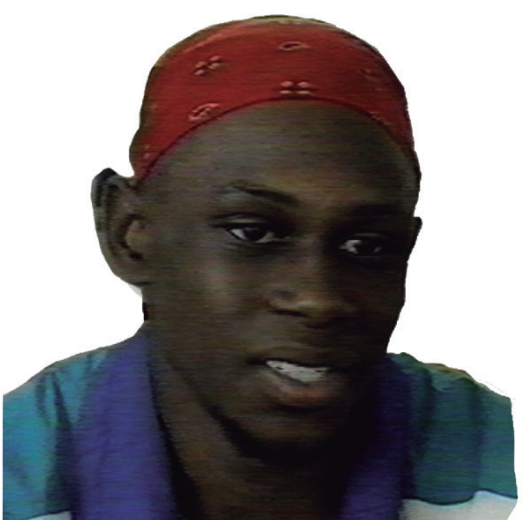

Figure 9 A student dancer interviewed by CNN

It is extremely important in the lower grades to involve the parents in understanding the science that their children learn so they can encourage them at home to pursue their studies. Therefore, it is important to conduct separate workshops for parents, teachers, and students and subsequently, combine the groups together. In the workshops, parents and teachers learn how to use art, music, dance, and drama in order to understand scientific concepts, and how to use household materials to perform science experiments which they could replicate in their own kitchens. In Figure 11 a mother and daughter are working together in their workshop.

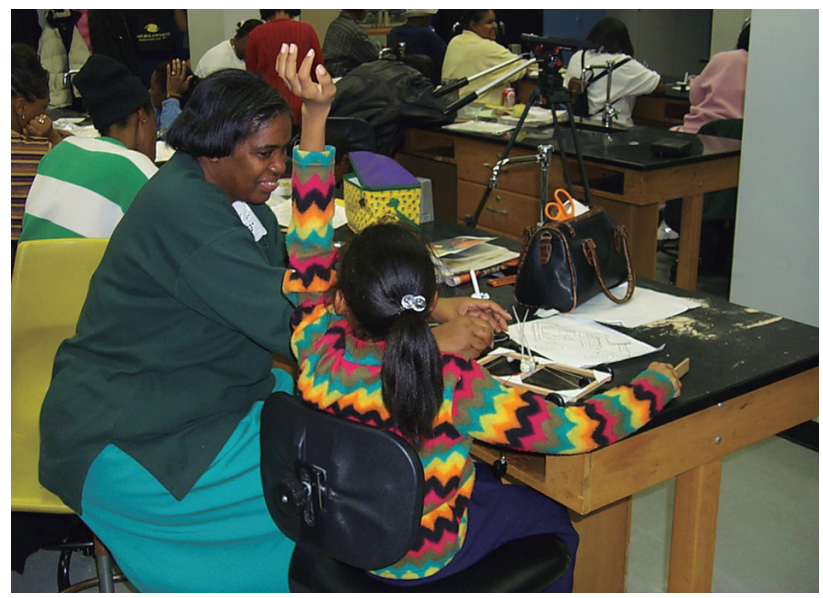

Figure 11 Student and Parent Workshops

\section{Results}

For five years teachers and students were evaluated after attending the workshops. In each school there was a class where 


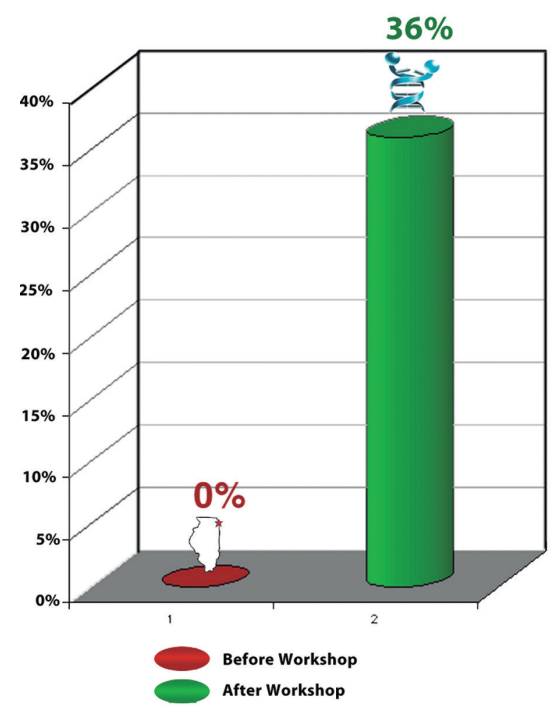

Figure 12 Teachers who reported feeling successful in providing science education to their students

teachers and students participated in the workshop, and a control class where the teachers and students did not participate.

The following graphs show the results of testing hundreds of teachers and parents, and thousands of students, comparing them to the control group.

As seen in Figure 12, the percentage of teachers who felt that they could teach science was $0 \%$ before the workshop. After the workshop, $36 \%$ felt very capable in teaching science.

As seen in Figure 13, there is a huge difference in achievement by students whose teachers and parents participated in the workshops, and children from the control group. The fifth grade and the eighth grade are very important grades in Chicago and other places in the U.S. After fifth grade students move from elementary school to middle school, and after eighth grade students move from middle school to high school.

These methods of teacing and learning fulfils my tenet in life, which prompted the creation of these methods - that equal access to science education is a human right that belongs to all.

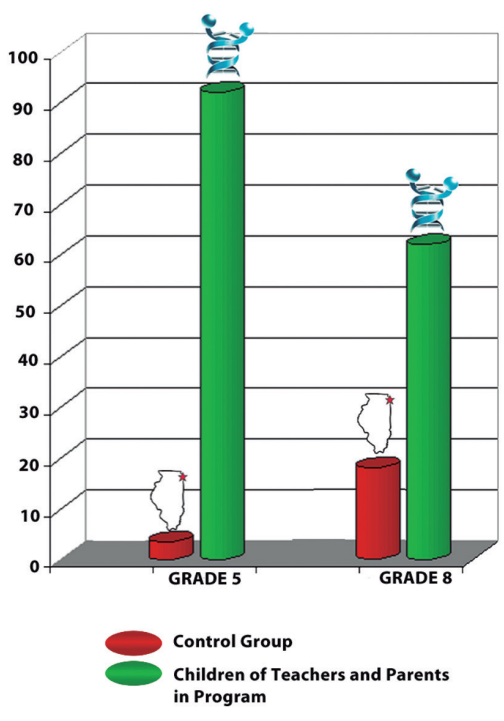

Figure 13 Differences in gain in student achievement for children whose parents and teachers participated in the workshops compared to that of students whose parents and teachers did not participate

\section{References}

Lerman, Z. M. 1986. Chemistry for Art and Communication Students: J. Chem. Ed., 63, 142.

Lerman, Z. M. 1986. Energy for Art and Communication Students: J. Chem. Ed., 63, 520.

Gardner, H. 1993. Multiple Intelligences: The Theory in Practice. Harper Collins, New York.

Hoffmann, R. and Torrence, V.1993. Chemistry Imagined: Reflections on Science. Smithsonian Institution Press, Washington, DC.

Lerman, Z. M. 2003. Using the Arts to Make Chemistry Accessible to Everybody. J. Chem. Ed., 80(11), 1234.

Lerman, Z. M. and Morton, D. 2009. Using the Arts and Computer Animation to Make Chemistry Accessible to All in the Twenty-First Century. In: Minu Gupta-Bhowon, Sabina Jhaumeer-Laulloo, Henri Li Kam Wah, Ponnadurai Ramasami (eds.). Chemistry Education in the ICT Age. Springer. pp. 31-39.

Lerman, Z. M. 2012. Creative Methods for Teaching and Learning Chemistry. In: Luigi Campanella (ed.). Stimulating Reflection and Catalysing Change in Chemical Education. Societá Chimica Italiana. pp. 196-201. 